\section{SOI: 1.1/TAS DOI: 10.15863/TAS International Scientific Journal Theoretical \& Applied Science}

\author{
p-ISSN: 2308-4944 (print) e-ISSN: 2409-0085 (online) \\ Year: 2017 Issue: 02 Volume: 46
}

Published: $23.02 .2017 \quad$ http://T-Science.org

SECTION 4. Computer science, computer engineering and automation.
R. I. Khasanov

Candidate of technical sciences, Assistant Professor of the department «Computer Science and Information Protection», Orenburg State University,

Russia, Orenburg hasanov0401@yandex.ru

A. I. Saraykin Lecturer of the department «Computer Science and Information Protection», Orenburg State University, Russia, Orenburg saraikin-a@yandex.ru

\title{
THE INTEGRATED SIMULATION MODEL OF A PROMISING ACTIVE SAFETY SYSTEM FOR THE EXECUTIVE CLASS VEHICLES
}

Abstract: In the article the authors developed an integrated simulation model of a promising active safety system for the executive class vehicles and the algorithm for positioning the group of vehicles in the conditions of visual information shortage based on the approach of a same virtual informational space.

Key words: drivers' computer support system, digitized roadway borders, satellite navigation tools, same virtual informational space, visual information shortage.

Language: English

Citation: Khasanov RI, Saraykin AI (2017) THE INTEGRATED SIMULATION MODEL OF A PROMISING ACTIVE SAFETY SYSTEM FOR THE EXECUTIVE CLASS VEHICLES. ISJ Theoretical \& Applied Science, 02 (46): 101-105.

Soi: http://s-o-i.org/1.1/TAS-02-46-19 Doi: crossef https://dx.doi.org/10.15863/TAS.2017.02.46.19

\section{Introduction}

For cars of high-ranking officials of the state there are special requirements for their active and passive safety. Different kind of provocation in the form of the creation of smoke or light curtains, spray paint substances on windshields or bad weather should not reduce the operating efficiency and safety executive cars. It is necessary to take into account the specifics of this particular class of vehicles, which are operated in a complex organized support group, the number of which reaches several tens of units $[1$; $2 ; 3 ; 4 ; 5 ; 8 ; 9 ; 10]$. Consequently, in the event of critical situations due to total or partial lack (deficiency) of visual and navigational information $\square$ business class car should be the guarantor not only of passive safety, for example, due to reliable armor protection, but do not allow potential saboteurs make confusion in action participants support, disrupt the safe and timely movement of VIPs. The development of these technologies is strategic in nature, it determines the prestige of the country and due to significant scientific- and capital intensity is not feasible without the direct involvement of the state, its academic and university organizations.

\section{Materials and Methods}

The difficult foreign policy situation once again confirms the need to develop its own advanced active safety systems, while necessarily taking into account the existing international experience of scientific schools and multinational corporations to create their own versions of high-precision positioning systems in cars conditions of lack of information.

One of the modern ways of solving this problem is to actively develop high-precision positioning systems for cars in advance digitized boundaries of the roadway using modern satellite navigation tools (SNT) new generation of wireless and information sharing technologies between vehicles throughout the support group.

There is also an urgent need to improve the information content of external executive cars using encrypted wireless communication channels and high-precision navigational information and technologies for display on the display board computer detailed position (orientation) of all participants in support groups.

The aim of section is to improve executive vehicles active safety under the conditions of insufficient visibility on the base of new methods and means of drivers computer support on roads.

To achieve this goal were solver following problems [6;7]:

$\square$ developed the conception of active safety improvement for executive class vehicles under the conditions of information shortage; 
$\square$ developed the integrated simulated model of perspective active safety and also algorithmic and software for vehicle positioning on road under the conditions of information shortage by means of SNT «GLONASS/GPS»;

$\square$ accomplished the analysis of movement of vehicles in poor visibility conditions using the developed prototype system.

The conception of work is based on generalization and systematization of progressive foreign and national experience in the area of active safety development, particularly with the use of SNT «GLONASS/GPS» and «V2V» technologies.

Drivers' computer support system (DCSS) structural diagram for the executive class vehicles is presented on figure 1 .

The input parameters are the following: $\square$ coordinates of latitude, longitude and altitude $K=\left\{x_{1}, y_{1}, z_{1}, x_{2}, y_{2}, z_{2}\right\}$ of vehicle location on satellite navigation tools data from antennas $M_{1}$ and $M_{2}$;

$\square$ setting parameter vector $R$ of vehicle positioning system on roadway;

$\square$ approximation method parameters $W=\left\{m_{i}\right.$, $d\}$, where $m_{i}$ - approximation algorithm, $d-$ approximation coordinated diapason of vehicle motion path;

$\square$ flow of video information $V_{R}$ under vehicle front axle;

$\square$ signals definition vector $Z_{t}$ at times $t$ from vehicle odometer;

$\square$ vector of longitude and transverse slopes $G_{t}$ $=\{p, r\}$ at time $t$ from angle of slope unit installed on the back axle of vehicle.

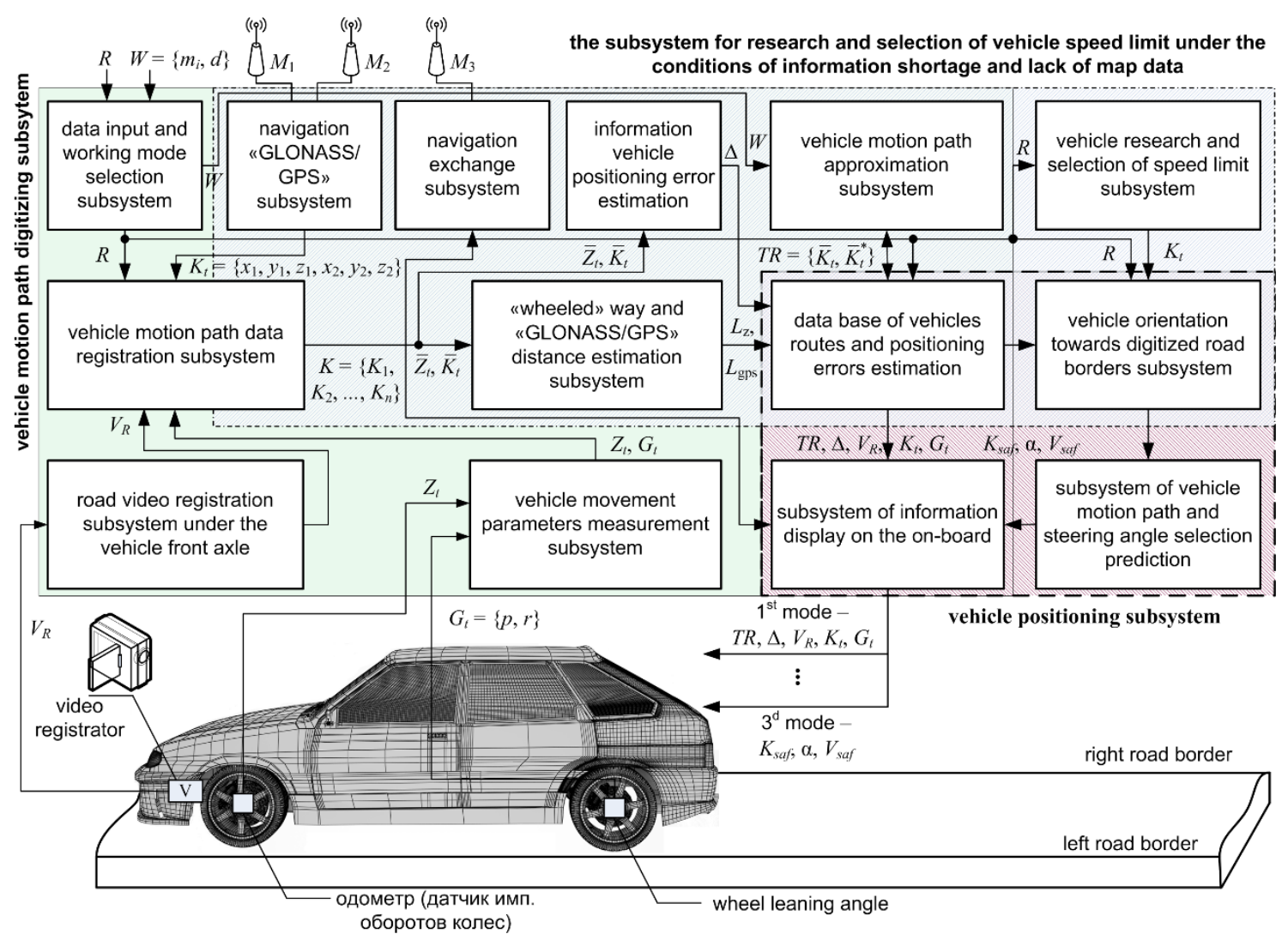

Figure 1 - DCSS structural diagram by executive class vehicles positioning moving in organized convoy (cortege) on the roadway under the conditions of VIS.

The presented system works in following modes $[6 ; 7]$ :

$1^{\text {st }}$ mode - automation of collecting, recording and processing data on the trajectory of car movement. This mode is also used in road mode digitizing boundaries, when the vehicle moves left and right sides of the road. Enroll navigational road coordinates boundaries derived vector coordinates undergo smoothing, produced histograms of probability distributions coordinate deviations from the smoothed line.

$2^{\mathrm{d}}$ mode - research and selection of high-speed car modes information deficit on different graphics primitives digitized road sections. This road is considered as an extended object in space whose boundaries are digitized with the desired increments. The input data for the selected mode are graphic primitives digitized road sections; the coordinates of 


\begin{tabular}{|c|c|c|c|c|c|c|}
\hline Impact Factor: & $\begin{array}{l}\text { ISRA (India) } \\
\text { ISI (Dubai, UAF } \\
\text { GIF (Australia) } \\
\text { JIF }\end{array}$ & $\begin{array}{l}=1.344 \\
=0.829 \\
=0.564 \\
=1.500\end{array}$ & $\begin{array}{l}\text { SIS (USA) } \\
\text { PИНЦ (Russia) } \\
\text { ESJI (KZ) } \\
\text { SJIF (Morocco) }\end{array}$ & $\begin{array}{l}=0.912 \\
=0.234 \\
=1.042 \\
=2.031\end{array}$ & $\begin{array}{l}\text { ICV (Poland) } \\
\text { PIF (India) } \\
\text { IBI (India) }\end{array}$ & $\begin{array}{l}=6.630 \\
=1.940 \\
=4.260\end{array}$ \\
\hline
\end{tabular}

the initial position of the first and second antennas navigators located, respectively, on the front and back parts of the body and determine the base; discrete obtain navigation data; vehicle speed of movement; the time scaling factor; the distance to the edge of the road, which must adhere to the vehicle. Selecting vehicle movement trajectory is carried out based on the geometric characteristics of an extended object and the desired speed of vehicle.

$3^{\mathrm{d}}$ mode - research of vehicle positioning mode in the absence of map data, as well as in conditions of poor visibility. This mode of operation of the system is also used as a guide for choosing a safe corridor of car movement in view of estimating the probability of hitting the edge of the shoulder of the road.

System output parameters depending on selected mode are the following:

$\square \quad 1^{\text {st }}$ mode - digitized motion path of mobile object $T R$, error estimation $\Delta$ of car positioning, video information flow $V_{R}$ under the front axle, coordinates $K$ of existing car positioning, angle of slopes $G_{t}=\{p, r\}$ of roadway;

$\square \quad 2^{\mathrm{d}}$ mode - graphics distance traveled as a function of the base and the vehicle speed until the deviations from the planned trajectory, when the vehicle is outside the allowed boundaries of the road;

$\square \quad 3^{\mathrm{d}}$ mode - recommended driving corridor recommended by a rotation angle and speed of the car in the conditions of lack of information.

The proposed system has a modular architecture, with all its subsystems are interconnected, change parameter values of one subsystem affects the output characteristics of the other.

On figure 2 presented the diagram of vehicle positioning moving in organized group under the conditions of information lack towards digitized road borders.

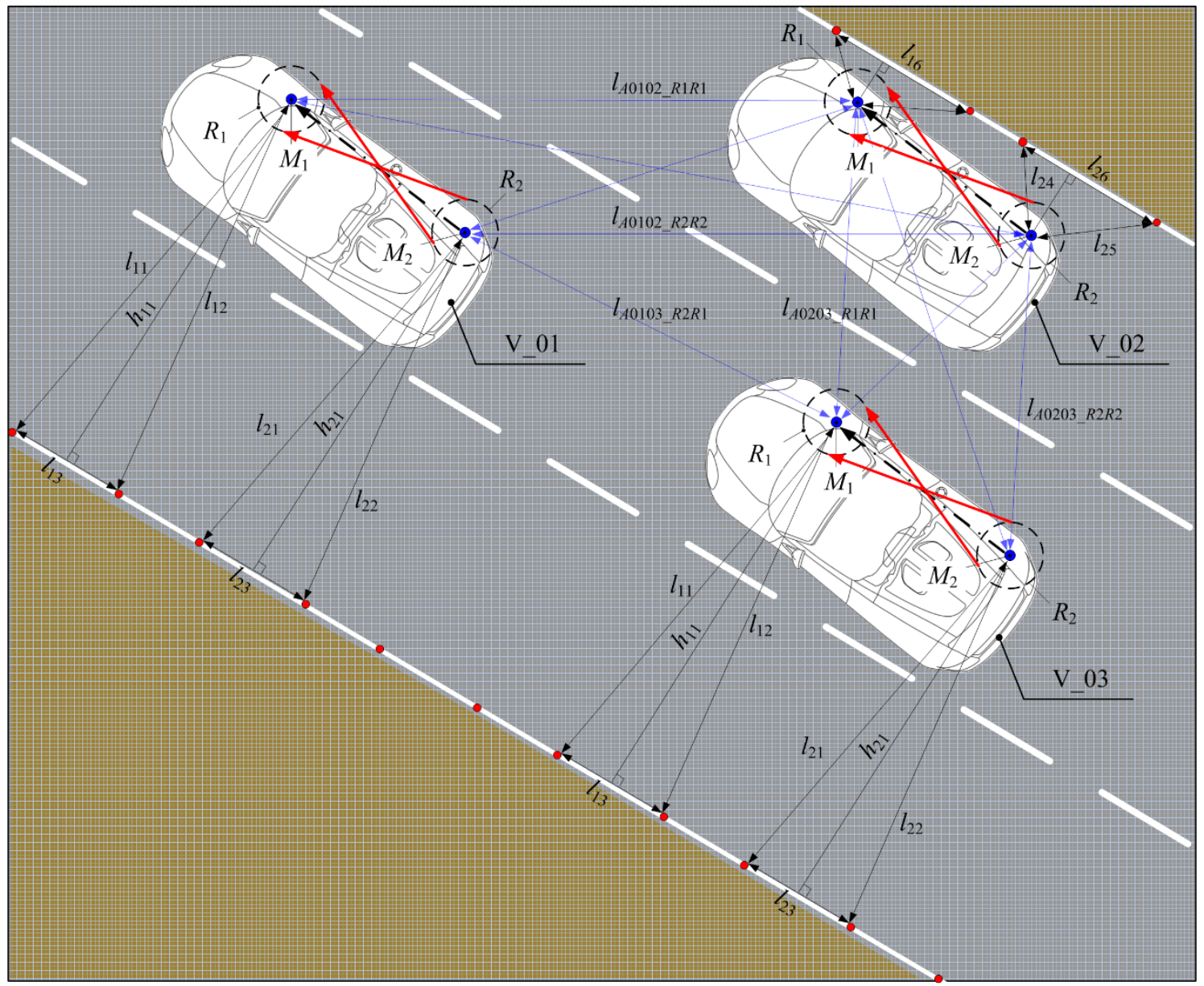

Figure 2 - The diagram of cortege positioning on the roadway.

The algorithm of positioning of vehicle group consists of following stages $[5 ; 6 ; 7]$ :

1. In on-board system of each car is given the discrete receiving navigation data and the accuracy of satellite navigation $-R_{1}$ and $R_{2}$. Database of digitized road borders the desired travel route is downloaded. 
2. In the process of vehicle driving the operator (navigator) uses evidence-board system to determine deviations from the recommended corridor of movement, taking into account the geometric characteristics of the road surface, the base of the vehicle, discreteness and errors of received navigation data.

3. The navigation coordinates of all the participants of support groups through exchange of navigation information subsystem input to the onboard system and form a single virtual information.

4. The same virtual informational space contains distance vectors between the vehicles and their location towards digitized road borders at each time $t$. Pointed parameters are displayed on the screen of on-board system.

Under same virtual informational space (SVIS) is meant the presence of all the participants of informational interaction (vehicle groups) equal copies of dynamic image $Q_{t}$, by changing of structure or content of which at time $t$ modified image $Q_{t}{ }^{\prime}$ becomes equally renewed for every member of informational interaction i.e. in all created copies. The example of SVIS method is the game «Sea Battle» and also modern computer online (command) games [7, 88 p.].

On commands the navigator driver performs positioning of the vehicle on the road: selects the vehicle speed, adhere to the regulated distance between the participants and to accompany the digitized boundaries of the roadway.

On figure 2 points $M_{1}$ and $M_{2}$ define the location of SNT «GLONASS/GPS» antennas for each group member - «V_01», «V_02» and «V_03». Circles $R_{1}$ and $R_{2}$ are error radiuses of satellite navigation. Distances $l_{11}-l_{26}$ define the lengths between digitized road borders and vehicle antennas location. Distances to digitized borders are $h_{11}-h_{22}$. Dash-and-dot line $M_{1} M_{2}$ defines the orientation of each vehicle towards digitized road borders and (or) road markings.

Distances $l_{A 0102 \_R 1 R 1}-l_{A 0203 \_R 2 R 2}$ between convoy participants is defined by navigational coordinates of antennas $M_{1}$ and $M_{2}$ for each vehicle taking into account car body dimensions and error radiuses $R_{1}$ and $R_{2}$ of SNT «GLONASS/GPS».

Each vehicle has its own unique identifier, for example the first vehicle in group has identifier «V_01», and the second one $-\left\langle\mathrm{V}_{-} \_2 »\right.$ and so on.

To coordinate all participants of convoy, in driver computer support system is created for each driver same virtual information space. Mentioned space is like multipage dynamic massive of complex system that is used by subsystems for selection of necessary recordings and positioning the vehicles under the conditions of information shortage.

The massive contains the following pages: navigation coordinates of all members of the group at each time point $\mathrm{t}$, the vector distances between them and their location relative to the digitized boundaries of the roadway.

\section{Conclusion}

The results can be recommended for the improvement of existing and development of new advanced active safety systems for motor vehicles. The greatest demand for computer support system drivers can receive a collection service for cars and to increase the active safety of vehicles of senior government officials, diplomatic and peacekeeping missions, subject to state protection.

\section{References:}

1. Bertozzi M (2013) A 13,000 km Intercontinental Trip with Driverless Vehicles: The VIAC Experiment / M. Bertozzi, A. Broggi, A. Coati et al. // IEEE Intelligent Transportation System Magazine. - 2013. - № 5 (1). $\quad-\quad$ P. $28 \quad-\quad 41$. doi:10.1109/MITS.2012.2225651.

2. Broggi A (2010) Sensing requirements for a 13,000 km intercontinental autonomous drive: In Procs. IEEE Intelligent Vehicles Symposium 2010 / A. Broggi, L. Bombini, C. Stefano et al. - CA, USA, June, 2010. - P. 500 - 505. doi:10.1109/IVS.2010.5548026.
3. Broggi A (2010) TerraMax Vision at the Urban Challenge 2007 / A. Broggi, A. Cappalunga, C. Caraffi et al. // IEEE Transactions on Intelligent Transportation Systems. - 2010. - Vol. 11, №. 1. $-\quad-\quad$ P. $194 \quad-\quad 205$. doi:10.1109/TITS.2010.2041231.

4. Gurin AS, Volkov VO, Makarov AV, et al. (2010) The way of vehicle moving in organized convoy safety provision: patent of the Russian Federation 2388057. №2007138126/11; applicant and patentee: Gurin Andrey Stanislavovich; dec. 15.10.2007; publ. 27.04.2010, bull. №12. - 11 p. 


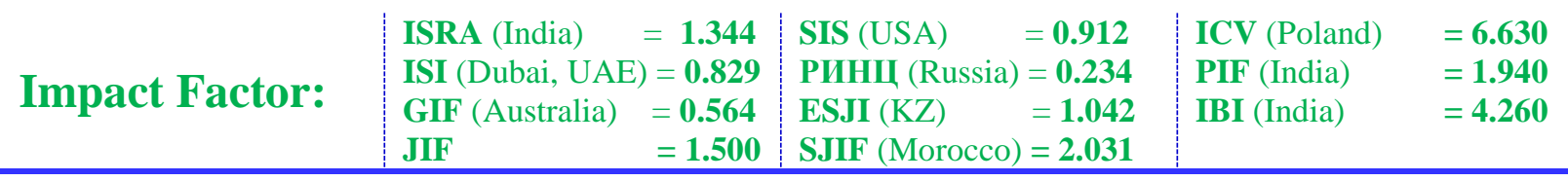

5. Khasanov RI (2016) Positioning method of multi-sectional wheeled vehicles on the roadway under the conditions of insufficient visibility / R.I. Khasanov // Magazine for automobile engineers. - 2016. - № 2 (97). - P. $32-35$.

6. Khasanov RI (2016) To the question of improving of top public officials active safety: source book of the $\mathrm{IV}^{\text {th }}$ international scientificpractical conference «Modern Problem of Health and Safety: Intelligent Transport Systems» / R.I. Khasanov, R.I. Khasanova. Russia, Kazan: SFI «Scientific Center of Health and Safety», 2016. - P. $554-561$.

7. Khasanov RI (2016) The positioning of organized group of mobile objects on the base of same virtual informational space / R.I. Khasanov, A.I. Saraykin // International technical and economic magazine. - 2016. - № 4. - P. $86-93$.

8. Ljahova VV (2015) Automated system to provide safety control for column motion of tactical wheeled vehicle / V.V. Ljahova // International scientific magazine. - 2015. №3-1. - P. 50 - 52.

9. Nagaytsev MV (2017) Project «Cortege»: Whereon Will the President Go? / magazine site «At the Wheel». Available: http://www.zr.ru/content/articles/672752proekt-kortezh-pervaya-seriya-na-chem-poedetprezident/ (Accessed: 14.02.2017).

10. (2017) Same module platform. RF government charged SSC RF FSUE «NAMI» the development of the vehicle for top public officials / site SSC RF FSUE «NAMI». Available: $\quad$ http://nami.ru/projects/emp (Accessed: 14.02.2017). 